\title{
La memoria transformadora como estrategia de intervención profesional en los procesos de reconciliación social: comprensión a partir de mujeres campesinas, excombatientes y jóvenes en Manizales, Colombia
}

\author{
Yeimmy Stephania Corredor-Sotelo \\ Trabajadora Social \\ Fundación Pulso. Bogotá, Colombia \\ https:/ / orcid.org/0000-0002-5613-6842 • stephaniacs04@gmail.com \\ Juliana Fuertes-Fuertes \\ Trabajadora Social \\ IPS municipal. Ipiales, Colombia \\ https:/ / orcid.org/0000-0001-8632-6367 • fuertesjuliana97@gmail.com
}

Resumen

Este texto es un acercamiento reflexivo para reconocer cómo actúa la Memoria Transformadora en medio de procesos de Reconciliación Social, involucrando elementos éticos y políticos que se manifiestan bajo la intervención profesional en medio de un contexto fracturado por el conflicto armado.

A través de esta reflexión, se pretende además reflejar las distintas dimensiones necesarias para construir procesos de Reconciliación Social, en medio de un acompañamiento estatal que propenda por la verdad, la justicia, la reparación y la no repetición de los actos violentos, llegando finalmente a unas consideraciones relacionadas al rol del Trabajador Social en medio de estos escenarios de conciliación.

Palabras clave: Memoria transformadora; Reconciliación Social; Intervención profesional; Sobrevivientes del conflicto armado; Jóvenes.

Recibido: 28/08/2020 |Aprobado: 17/11/2020 |Publicado: 01/01/2021

(c) (i)(2) Esta obra está bajo una Licencia Creative Commons Atribución-NoComercialCompartirIgual 4.0 Internacional.

Financiación o proveniencia del artículo: artículo derivado de la sistematización La vida después de la guerra del proyecto social "Rescatando los saberes y sabores de las abuelas: una apuesta de reparación, reconciliación y emprendimiento social” realizado en el año 2019, avalado por Universidad de Caldas, Colombia.

¿Cómo citar este artículo? / How to quote this article?

Corredor-Sotelo, Y. S., y Fuertes-Fuertes, J. (2021). La memoria transformadora como estrategia de intervención profesional en los procesos de reconciliación social: comprensión a partir de mujeres campesinas, excombatientes y jóvenes en Manizales, Colombia. Prospectiva. Revista de Trabajo Social e intervención social, (31), 221-240. doi: 10.25100/prts.v0i31.10546. 
Corredor-Sotelo y Fuertes-Fuertes

\title{
Transformative Memory as a Strategy of Professional Intervention in Processes of Social Reconciliation: Comprehension from the Perspectives of Peasant Women, Ex-combatants and Youth in Manizales, Colombia
}

\begin{abstract}
This text is a reflective approach to recognize how Transformative Memory acts in the midst of Social Reconciliation processes, involving ethical and political elements that manifest themselves under professional intervention in a context fractured by the armed conflict.

Through this reflection, the aim is to reveal the different dimensions necessary to build processes of Social Reconciliation in conjunction with state accompaniment that promotes the truth, justice, reparation and non-repetition of violent acts. The reflection finally discusses some considerations related to the role of a Social Worker in such scenarios.

Keywords: Transformative memory; Social reconciliation; Social intervention; Survivors of the armed conflict; Young people.

Sumario: 1. Introducción, 2. Metodología, 3. Hallazgos 3.1. Comprensiones sobre la intervención, 3.2. El rol profesional en escenarios de construcción de paz, 4. Conclusiones, 5. Referencias bibliográficas.
\end{abstract}




\section{Introducción}

El contenido de este artículo corresponde a la sistematización La vida después de la guerra desarrollado bajo el proyecto social, denominado Rescatando los saberes y sabores de las abuelas: una apuesta de reparación, reconciliación y emprendimiento social, orientado desde el Centro de estudios sobre conflicto, violencia y convivencia social (CEDAT) en la universidad de Caldas, Manizales, el cual se desarrolló en dos fases principales: la primera de ellas, orientada a la construcción de narrativas y experiencias de sobrevivencia de mujeres campesinas y excombatientes en proceso de reintegración y reincorporación, en el marco de prácticas de cuidado y de restauración de relaciones fragmentadas por la violencia armada, desarrolladas en la huerta y en la cocina, como escenarios de ejercicio político y de resistencia a la invisibilización y reconocimiento de la vida, proyecto que tuvo origen y desarrollo en un espacio gestado por la Universidad de Caldas en la ciudad de Manizales.

La segunda fase, orientada al reconocimiento de dichas narrativas y experiencias de sobrevivencia por parte de jóvenes ubicados en contextos escolares de la comuna universitaria, con quienes, a través de la metáfora de la siembra, se buscó reflexionar sobre asuntos fundamentales para construir Reconciliación Social. Los jóvenes son la generación llamada a dinamizar y construir opciones encaminadas a configurar una comprensión respecto al valor de la vida, de la convivencia social, de los Derechos humanos, de la libertad y de la justicia social, reconociendo la importancia de los escenarios educativos en el marco del contexto actual del país, donde se impone de manera inicua una distribución inequitativa de los recursos, unos órdenes sociales injustos, unas prácticas cotidianas fundamentadas en relaciones hegemónicas de subordinación y eliminación de los otros y lo otro, un momento histórico, en el que los jóvenes tienen la responsabilidad y oportunidad de configurar otro tipo de relaciones, caracterizadas por el respeto a las diversas formas de vida que hagan posible la convivencia y la justicia social.

En el marco de este proyecto emerge el proceso de la reconciliación social como apuesta política: recordando el pasado y proyectando el futuro, que pretende aportar desde la memoria transformadora a la conciliación de relaciones sociales fracturadas, a partir de las experiencias vividas en el marco del Conflicto armado.

De esta manera se entiende el proceso como una posibilidad de encuentro de saberes y de experiencias cotidianas, encaminada a construir en colectividad y desde la reflexividad, una comprensión y formas particulares de habitar el mundo; por tanto la metáfora de la siembra emerge como guía metodológica que orienta la acción en la construcción de un sentido compartido frente a lo que nos es común, la relación con la tierra, objeto de tensiones y de conflictos, pero también generadora de posibilidades de reconstrucción y de continuidad de la vida después de la guerra. En esta relación se pretende reconocer valores, principios, saberes y opciones para construir un mundo en colectivo; en consecuencia, la 
Corredor-Sotelo y Fuertes-Fuertes

pregunta aparece como elemento movilizador, siempre en relación directa con lo que el sujeto es, su contexto y su relación con el otro, por tanto, se manifiesta como la posibilidad de estar en continuo cuestionamiento, dando apertura a encontrar múltiples respuestas, que ofrezcan un panorama amplio y consecuente con las dinámicas de la realidad social.

Finalmente, esta es una invitación a repensar conjuntamente las iniciativas de Reconciliación Social a partir de las historias de sobrevivencia, que desemboquen en encuentros con la memoria, en este caso, con una memoria que transforme, encamine y resignifique las historias dominantes y las percepciones polarizadas alrededor del conflicto armado colombiano, como una posibilidad para construir un país más incluyente, equitativo y justo.

\section{Metodología}

El desarrollo de este artículo se realizó a partir de la experiencia de un proceso de práctica profesional y su respectiva sistematización, además de una revisión documental sobre investigaciones para la paz y la reconciliación, los múltiples trabajos de memoria emprendidos en Colombia, la intervención, la ética y el rol del Trabajador Social.

El proceso metodológico orientado a través de la metáfora de la siembra contempló tres momentos:

- Preparar y abonar el terreno: se orienta a dar apertura y/o construir espacios de acercamiento con el otro, donde se pueda escuchar, sentir y expresar aquellas construcciones individuales sobre si, el otro y la realidad actual. Para el caso, se pretendió situar de forma contrastada las experiencias de vida de los jóvenes y los sobrevivientes del conflicto armado mediante encuentros mediados por el conocimiento y la visibilización de las narrativas facilitando el reconocimiento de la vida de otros a través de la vida propia, aproximaciones y lejanías.

- Sembrar: se orienta a generar cuestionamientos y reflexiones sobre las capacidades y/o limitaciones individuales y colectivas que pueden incidir en la construcción de procesos de Reconciliación Social. Para el caso, implicó que los actores involucrados en el proceso reflexionaran sobre sus saberes y sus experiencias durante y después de la guerra, así como en contextos cotidianos alejados de esta, donde identificaron elementos posibilitadores de la construcción de Reconciliación Social además de preguntarse sobre la realidad actual del país, empezar a cuestionarse las relaciones de poder y las injusticias.

- Cuidar el terreno y cosechar: se orienta a emprender acciones que posibiliten la transformación de hechos o situaciones injustas que emergen en medio del 
Corredor-Sotelo y Fuertes-Fuertes contexto social a través de las construcciones, resignificaciones y posicionamientos ético-políticos de los sujetos participantes. En ese sentido, dentro de la experiencia implicó que las mujeres campesinas, los jóvenes y excombatientes en proceso de reintegración y reincorporación se reconocieran como agentes de transformación en los procesos de Reconciliación Social.

El proceso se desarrolló bajo un enfoque dialógico que permitió, a partir de la pregunta, develar discursos y principios de la memoria transformadora. Este enfoque logró guiar las reflexiones dadas por los sujetos, en este caso concreto, desde el acercamiento con mujeres campesinas, los jóvenes y los excombatientes, emancipando y construyendo sus propias oportunidades de continuar una vida después de la guerra.

Para la consolidación de este escrito, la información fue recolectada a partir de la revisión documental de varios autores, algunas entrevistas semiestructuradas -a las mujeres campesinas, los reincorporados, los reintegrados y los jóvenes en contextos escolares- y la observación participante, presta en medio del proceso.

En lo que corresponde al proceso de codificación, este se realizó con la ayuda de un programa informático utilizado en investigación cualitativa denominado ATLAS.ti: se crearon cuatro unidades hermenéuticas correspondientes a instrumentos como diarios de campo, entrevistas, fichas analíticas y fotografías, con el fin de sustraer a partir de dimensiones o códigos emergentes en la construcción de la metodología aquellos relatos, narraciones, percepciones y reflexiones gestadas en medio de la experiencia; adicionalmente, se dio paso a una serie de reflexiones que permitieron ir configurando nuevas formas de comprender el proceso, desde un análisis triangular que nos permitió entender a los autores, los sobrevivientes y los jóvenes en contextos escolares, desde una mirada profesional.

\section{Hallazgos}

Lo que se presentará como hallazgos son distintas formas de comprender la intervención profesional a partir del desarrollo de 7 asuntos fundamentales para construir Memoria Transformadora en medio de procesos de Reconciliación Social.

\subsection{Comprensión sobre la intervención}

Esta experiencia permitió develar ciertos elementos que configuran la intervención profesional en el marco de procesos de Reconciliación Social. Así entonces, la Memoria Transformadora actúa como estrategia de intervención, pues se entiende que no es posible 
construir Reconciliación Social sin memoria, sin una memoria, que más allá de tener pretensiones de verdad, se asuma como una posibilidad, como un acto cotidiano:

Donde se conecta la dimensión de la experiencia (aquello que ha sucedido a alguien y de lo que es posible dar cuenta -por ejemplo- narrativamente) con la dimensión de la expectativa (lo que aún no es, pero que se presenta como guía de acción). (Jaramillo y Torres, 2014, p. 2)

En esa medida, la intervención desde Trabajo Social como un proceso con sentido e intencionalidad se construye en relación constante con los sujetos y sus contextos particulares, que a su vez orientan el accionar profesional. Este proceso motiva la reflexión frente a situaciones sociales no resueltas, implica un posicionamiento ético y político que trascienda las miradas asistenciales y posibilite una mirada crítica y emancipadora de la realidad, ampliando la comprensión y develando los distintos lenguajes que se enmarcan dentro de la experiencia.

En medio de ese sentido e intencionalidad que se le adjudica a la intervención se plantea que para construir Reconciliación Social desde la Memoria Transformadora es necesario:

\subsubsection{Reconocer que la vida se construye y reconstruye desde lo cotidiano}

De allí, la importancia de reconocer los escenarios y las prácticas que configuran la identidad de los sujetos, en el caso de este proceso, por ejemplo, se asumió que tanto la cocina como la huerta son escenarios en los que se recrea la vida, donde se recuperan distintos saberes del campo, se fortalece y sostiene la identidad de muchos de los sobrevivientes del conflicto armado, generalmente campesinos, posicionándose como lugares para restaurar las relaciones entre sobrevivientes y la naturaleza en tanto posibilidad de mantener en la ciudad vínculos caracterizados por el cuidado, la solidaridad, la cooperación y el servicio, elementos de importancia a la hora de significar y recordar lo denominado como hogar. Lo cotidiano permite a través de la experiencia acercarnos al otro, reconocerlo desde aquello que es, compartir asuntos comunes en el marco de la diversidad, en medio de esta cotidianidad se da también apertura para desaprender formas de relacionarnos dicotómicas, autoritarias, fraccionadas e individualistas, gestadas desde muy temprana edad por un modelo bancario que no da posibilidad a pensar diferente, que no promueve el diálogo, la conversación, la escucha y a la vez el reconocimiento; por ello lo cotidiano, se convirtió para este caso en un espacio también de tensión, de confrontación, de lucha y de resistencia como un medio para lograr consolidar un ejercicio de Memoria Transformadora.

Entonces, es a medida que se avanza en la experiencia que la Reconciliación Social se logra concebir como un proceso, que se rige bajo un principio de voluntariedad, el cual 
Corredor-Sotelo y Fuertes-Fuertes

aparece en medio del convivir juntos, despierta de manera simultánea sujetos que se piensan desde sus historias de manera ética y política, pero ¿qué implica lo ético y lo político en estos procesos? En el marco de lo ético, la promoción y la defensa de la vida humana y los derechos son los principios que orientan la humanización en medio del conflicto, lo ético fortalece la democracia e invita al cumplimiento del Estado social de derecho que se expresa en la Constitución.

Para el caso de esta experiencia, la Memoria Transformadora permitió repensar a las mujeres desplazadas, los excombatientes y a los jóvenes ubicados en contextos educativos en perspectiva de futuro, en vía a la transformación y significación de sus experiencias en el marco de la violencia armada en Colombia, de manera distinta junto a otros. "(...) el hacer y el tejer es, o debería ser siempre en el horizonte, un acto ética y políticamente solidario, no solitario" (Jaramillo y Torres, 2014, p. 2) donde se pretendió que tanto los jóvenes como las mujeres y los excombatientes, a través de sus experiencias, se responsabilizaran de continuar construyendo país en clave de justicia y convivencia social.

... la Ley 1448 de 2011 de Víctimas y Restitución de Tierras, referida al conflicto armado, que incorpora aspectos de tipo socio-político. Esta ley puede entenderse como un instrumento dirigido a la reconciliación, pues reúne la reparación integral de los daños físicos y psicológicos por el conflicto armado y las omisiones y aspectos estructurales que han impedido la vida plena y digna: el acceso a la tierra, las condiciones de participación, etc. (Bloomfield, Fernández y Angulo-Novoa, 2015, p. 41)

Lo político y el diálogo que deriva de él explora el pasado y la importancia de la significación que los diversos actores involucrados en el conflicto le otorgan a la construcción de un futuro conjunto; también permitirá tramitar los conflictos de manera distinta desprendiendo unos alcances en relación a la coexistencia como micro proceso que implica cierta actitud frente a la vida colectiva que promueve: "espacios de deliberación en condiciones igualitarias que permitiría la toma de decisiones conjuntas y democráticas sobre el futuro que esa sociedad quiere" (Méndez, 2011). Como mínimo, esta inclinación sugiere reconocer los derechos mutuos para habitar un espacio sin violencia, con el cual se puede lograr la reconciliación; esta coexistencia implica aceptar de manera voluntaria un nuevo estado de cosas, que desemboque en la consolidación de la convivencia pacífica como resultado próximo a la reconciliación que involucra nuevas relaciones de confianza entre ciudadanos e instituciones que, a la vez, reconcilie también las múltiples verdades bajo un escenario que garantice la superación de la dicotomía entre víctima y victimario, favoreciendo el respeto mutuo, las diversas formas de organización, el restablecimiento de las relaciones fragmentadas y la construcción de nuevos consensos bajo la lógica de la participación en sus variadas expresiones. Es de esta manera que lo político exige acuerdos sobre formas de vida justas y dignas dirigidas a la paz y a la convivencia. 
Corredor-Sotelo y Fuertes-Fuertes

3.2.1 Comprender dentro de los procesos de Reconciliación Social sus distintas dimensiones ${ }^{1}$

En lo que se ha comprendido a lo largo de la experiencia y con el acercamiento a varios autores, esta primera dimensión interpersonal está asociada a dos maneras fundamentales de entenderla, una, un poco más orientada a principios religiosos del perdón entre víctima y victimario, otra, dirigida a encuentros terapéuticos de superación y tramitación del dolor, esta última, enfocada mucho más en la idea de reconciliación construida hasta ahora. Lo que se pretende en medio de la tramitación del dolor es, a través del reconocimiento, liberarlo del cuerpo que lo ha sufrido "aprisionado en el interior del sujeto solitario" (Ortega, 2008, p. 264).

El término reconocimiento [...] proviene de la filosofía hegeliana [...] en esta tradición el reconocimiento designa una relación recíproca ideal entre sujetos en la que cada uno ve al otro como su igual y también como separado de sí. Se estima que esta relación es constitutiva de la subjetividad: uno se convierte en sujeto individual sólo en virtud de reconocer a otro. (Fraser y Honneth, 2003, p. 20)

En ese sentido, hacer memoria sobre las historias de vida de los sobrevivientes del conflicto armado en relación con las historias de vida de los jóvenes ubicados en contextos escolares implicó comprender que "la experiencia es "eso "que nos pasa", una relación con algo que no soy yo, pero que tiene lugar en mí” (Larrosa-Bondía, 2010, p. 93), desde allí, se puede conocer, comprender e interpelar las distintas historias que emergen en medio de las confrontaciones armadas, permitiendo develar asuntos estructurales que inciden en la consolidación de la violencia. Esta conexión entre historias, no solo permite involucrar los hechos que han fracturado la vida, sino también las construcciones antes, durante y después de dicha experiencia, haciendo evidente el cambio, las reinvenciones y el descubrimiento de diferentes capacidades para transformar, construyendo desde el reconocimiento elementos que movilicen a partir de la confrontación con otras realidades.

Es en esta dimensión interpersonal que la Reconciliación Social como proceso, cobra verdadero significado, es allí donde la voluntariedad como elemento político sale a flote, pues implica profundas transiciones centradas en las emociones, el reconocimiento y la sanación, enfoques más subjetivos y psicológicos que se conforman mediante un proceso social, hacia otros y desde otros. Como resultado, la tramitación del dolor es necesaria dentro de los procesos de Reconciliación Social, permite conectarse con el otro y asumir un compromiso colectivo, la afectación por lo que el otro siente deriva en unificación a una lucha colectiva, la indignación como emoción política que permite transcender.

1 Estas tres dimensiones dan cuenta de una reconciliación concreta en un contexto de violencia como el colombiano. 
Ahora bien, el reconocimiento como imperativo moral involucra ponerse en los zapatos del otro como posibilidad para restituir un vínculo fracturado o que apenas inicia su consolidación. Presupone de esta manera conocer la historia, el lenguaje que se externaliza de la experiencia personal que permite acercarnos al dolor subjetivo, al dolor de quienes son sobrevivientes, para darle el reconocimiento y la visibilidad por la que aboga Ortega (2008, p. 293). Este reconocimiento muy relacionado con la justicia social que engloba a la vez una redistribución, se encamina a promover la diferencia como condición necesaria para la formación práctica de la identidad personal y establece una contemplación crítica del contexto en el que se está inmerso, que involucra esencialmente componentes económicos, políticos y culturales. Otros autores que han logrado tener un acercamiento mucho más riguroso con el estudio de la violencia socio política en Colombia han afirmado y segmentado varias categorías en medio de los procesos de desvictimización, proponiendo una linealidad que se extiende hasta la categoría de supervivencia.

\begin{abstract}
En la episteme de la victimidad, las víctimas están sujetas al daño ontológico como subvivientes, prefijo que significa que son puestas por debajo de las condiciones de existencia y de la proyección de vida que tenían antes del perjuicio que se les ocasionó; son ubicadas (o pueden hacerlo por sí mismas) en la posición de sobrevivientes ya en el campo de la lucha por sus derechos, sea en un dispositivo penal, transicional o restaurativo; y de la misma manera pueden lograr reposicionarse más allá o por fuera de la reparación, hasta ocupar un lugar de dignidad como supervivientes. (Acevedo-Arango, Serrano-Quintero y Cuartas-Giraldo, 2019, p. 83)
\end{abstract}

Posicionando acciones que permiten redefinir un rumbo, un proyecto y un plan de vida. En medio de este proceso, la Memoria Transformadora aparece como una estrategia de reflexión que implica problematizar, pensar, considerar y comprender la razón de ser de esta, la recuperación e interpretación de la historia en relación con la experiencia de los sujetos, los cuales se asumen y se enuncian desde el ideal de transitar del hecho victimizante a una experiencia de sobrevivencia y procesamiento del dolor, no solo como aquello que pasó sino también sobre lo que los sujetos hacen con lo que les aconteció. Es así como se convierte en un eje fundamental, pues permite pensar a los sujetos en perspectiva del futuro, reconociendo la capacidad de cada uno de transformar los contextos más próximos desde las acciones presentes tras una experiencia significativa.

Ahora, en la dimensión que involucra la relación con los otros aparece la sociedad civil como actor indirecto, del cual, en medio de las transiciones de esta experiencia se desprenden los jóvenes. En esta dimensión está envuelto todo aquel ajeno y desconocido, que se permite a partir del diálogo, el debate y la interpelación, nuevas posturas y consensos que convergen en nuevas realidades, emergiendo nuevas formas de relacionarse y comunicarse, propendiendo al igual que la primera dimensión al reconocimiento del otro, de lo que piensa, de lo que sabe y de lo que ha vivido, un acercamiento al estudio de las subjetividades que permite encontrar puntos de vida que los aproximen y los haga comunes. Así, la interacción con otros implica la convivencia del día a día, aspira a pensarse

Prospectiva. Revista de Trabajo Social e intervención social • No. 31 • ene.jun. $2021 \bullet$ pp. 221-240 e-ISSN: 2389-993X • https:// doi.org/10.25100/prts.v0i31.10546 
a nivel estructural aquellas limitaciones ideológicas y políticas que plantean dualidades entre amigos y enemigos, lo bueno y lo malo, la víctima y el victimario.

Construir Memoria Transformadora en medio del proceso de Reconciliación Social, con sobrevivientes del conflicto armado y jóvenes en contextos educativos, implicó sensibilizar y visibilizar la historia de cada uno, no desde la individualidad, al contrario, siempre en relación o interacción constante con el otro, permitiendo que la construcción se presentara de manera mucho más enriquecida, pues el debate, el diálogo y el intercambio de experiencias y significados dotaron las historias de vida de sentidos diferentes, que a su vez permitieron proyectar el futuro desde posturas y acciones más reflexivas, críticas y cotidianas a partir de representaciones como la huerta y la cocina para el caso de los sobrevivientes, sobre las cuales no solamente resignificaron sus historias en el marco del conflicto armado, sino también desde otras experiencias de vida, donde los saberes que aprendieron en el campo tomaron gran protagonismo dentro del proceso, permitiendo retomar otros elementos y configuraciones nuevas sobre la acción. En consecuencia, la siembra y la preparación de alimentos se convierten en acciones propicias para la sanación, la construcción colectiva de memoria y la resistencia; para el caso de los jóvenes, implicó traer al presente historias cercanas de sobrevivencia, cuestionar su contexto y la violencia presente, dar cuenta de la situación actual del país, comprender sus limitaciones y posibilidades para construir paz y a la vez poner en duda el futuro tras la activación de sus capacidades y la nueva manera en la que pueden proyectarse en él.

Este proceso extremadamente complejo implicó incluso la participación de varias generaciones, los jóvenes, quienes orientarán el futuro del país y emprenderán a partir del fortalecimiento ético y político procesos de reivindicación y defensa de los Derechos Humanos. Para ello es necesario que puedan reconocer que tienen la capacidad para transformar desde pequeñas acciones, que orientan una convivencia basada en el respeto por el otro, donde se deslegitime toda acción que atente contra la justicia, la equidad y la dignidad humana, acciones que se construyan en el marco de un sistema democrático, posibilitando el ejercicio libre de los derechos donde se reconozca y respete los procesos de participación y de representación que buscan la construcción de una sociedad orientada a la dignificación, preservación y transformación de la vida, influyendo no solo en el fin de la violencia, sino haciendo parte esencial del desarrollo y la consolidación de la Reconciliación Social en un sociedad altamente fracturada como la colombiana.

Sumándose a las dos anteriores dimensiones, en esta tercera y última que concierne a la Relación que se teje con lo otro, es importante dirigir la atención a la construcción de paz y a los procesos de Reconciliación Social que exigen abordajes integrales y de largo plazo que conduzcan a la superación de diversas conflictividades; es por esto, que esta dimensión involucra al Estado como forma de organización social y a las diferentes instituciones y organizaciones gubernamentales, también, refleja la necesidad de reconciliarse con la 
naturaleza, con la tierra como espacio de disputas del poder y dominación marcadas, que se reproducen en las instituciones y en las relaciones sociales para conservar condiciones jerárquicas y desiguales en las cuales se inscribe la subordinación, la opresión y hasta la eliminación del otro, que se despliega bajo mandatos sociales injustos que se deben reformar.

En medio de procesos de Reconciliación Social, es indispensable mencionar que el acompañamiento de los actores estatales, personas e instituciones que administran y dirigen un Estado es fundamental, pues se entiende, que en el desarrollo de un contexto de conflicto armado, el Estado cumple un papel protagónico en vías a un sistema jurídico integral que comprenda la verdad, la justicia, la reparación y la no repetición de los hechos violentos, impulsando la reconstrucción de relaciones fragmentadas, que caracterizan un proceso de largo plazo, que requiere la reforma profunda de ciertos imaginarios sociales arraigados, con el fin de generar nuevos consensos que garanticen que la violencia del pasado no se repetirá. "En una sociedad caracterizada por una profunda polarización e inequidad social como la colombiana, los avances hacia la reconciliación implicarán no solo (re) construir las relaciones y la confianza, sino cerrar las brechas de la exclusión económica, social y política" (Centro de Investigación y Educación Popular [CINEP] y Organización Internacional para las Migraciones [OIM], 2015, p. 174).

Por ello, es necesario entender la reconciliación no solo desde una coyuntura o momento álgido a nivel político y social, como la firma de unos acuerdos y la reconstrucción de relaciones quebrantadas por la violencia, es propicio entenderla también desde las condiciones desiguales, desafortunadas, injustas y de empobrecimiento de la mayoría de la población, comprendiendo así que es un proceso que demanda una conciliación de relaciones que, al no estar satisfechas las necesidades básicas de sobrevivencia, desencadena poca participación de los actores en dichos procesos. La dignidad (noción imprescindible para alcanzar la felicidad) como valor supremo "ha encontrado su mejor definición en el concepto de derechos prelegales (Derechos subjetivos, innatos, derechos morales [...]) que a su vez se han concretado en los llamados Derechos Humanos" (Marina-Torres y De la Válgoma, 2005). Del reconocimiento de la dignidad dependen la libertad, la justicia y la paz. Entonces, debe estar presente para cuando se piensa la Reconciliación Social en cualquiera de estas dimensiones.

\subsubsection{Reconocer y comprender la existencia de múltiples verdades}

La comprensión sobre la verdad, la justicia, la reparación y la no repetición en medio de estos procesos de conciliación es fundamental, pues garantiza un proceso perdurable y de reconocimiento recíproco. Partiendo de esta premisa, la verdad, que comprende el sistema jurídico de que dispone el gobierno debe estar orientada a la Reconciliación Social en busca de la reconstrucción del pasado. Es a partir de este elemento que se introduce la 
Corredor-Sotelo y Fuertes-Fuertes

memoria como objeto de estudio en medio de estos procesos, para salir o transitar de una memoria de la violencia a una mucho más transformadora. Esta noción reconoce que por medio del diálogo y la negociación se contribuye a la consolidación de la paz de una nación, se reconocen los daños ocasionados y aporta a la dignificación de los sobrevivientes al conflicto armado.

La verdad se constituye como un elemento para entender el porqué de lo sucedido y en ese mismo sentido la dimensión del dolor. No se trata de buscar una única verdad, puesto que se reconocen las múltiples verdades que sobresalen en medio de la reconstrucción de un pasado violento, se trata de hacer un esfuerzo por reconciliar también las verdades en un espacio que garantice la coexistencia y la convivencia pacífica. Nuevamente la memoria surge en medio de un reconocimiento y circulación de la verdad.

El reconocimiento de los hechos por los autores y de la responsabilidad del Estado, así como las acciones que ayuden a asumir la verdad como parte de la conciencia moral de la sociedad, son parte de la reparación de la dignidad de las víctimas y mejora la vida de los sobrevivientes. (Bueno-Cipagauta, 2006, p. 72)

Esclarecer y narrar la verdad consiste en reconocer experiencias, descubrir sucesos desconocidos, dar lugar a quienes no han sido escuchados; es primordial en medio de la verdad un involucramiento y una reforma de los aparatos estatales que nos coaccionan, pues si dejamos de lado esta concepción, estos procesos de Reconciliación Social serán poco realizables.

\subsubsection{Pensar la Justicia Social desde su integralidad}

La Justicia Social que transversaliza nuestra profesión tiene dos miradas importantes desde las cuales abordar estos procesos de reconciliación, una de ellas es desde la distribución y el reconocimiento -planteamientos estudiados por Fraser (2000) -. Esta categoría de Justicia como elemento fundamental de los Derechos Humanos, se comprende como eje esencial para la construcción colectiva, enfocándose en la consolidación de la identidad desde una perspectiva relacional y situacional. "La justicia en una sociedad diferenciada por grupos demanda la igualdad social de los grupos, y el mutuo reconocimiento y afirmación de las diferencias de grupo" (Grueso, 2008, p. 58). Otra, busca por medio de una justicia más restaurativa, la participación de todos los llamados a reconciliarse, actores sumergidos de manera directa en el conflicto -sobrevivientes- así como los indirectos, sociedad civil que en relación con el Estado pretende restaurar y fortalecer en medio de estos procesos las relaciones fragmentadas.

La justicia desde el reconocimiento y la restauración, trasciende su posición netamente punitiva en un intento por reconciliar aquellas relaciones fracturadas a raíz del conflicto, es 
un proceso más participativo que de nuevo hace uso del diálogo y los consensos que derivan del mismo, se centra en las necesidades y obligaciones de los sujetos, estimula la empatía y la responsabilidad. Bajo este panorama, no se desea disminuir la importancia de la justicia redistributiva, claramente desempeña un papel primordial, sin embargo, una sociedad justa no depende solamente de esta distribución monetaria a poblaciones vulneradas, exige desde otras miradas de la justicia a la complementariedad de esas distribuciones, reconociendo los diferentes sectores, sus necesidades, sus limitaciones y su falta de oportunidades, negadas en su mayoría por un Estado ausente. En este punto y tras esta premisa se logra vislumbrar la memoria social como otro concepto de gran importancia a la hora de comprender la restauración de los sobrevivientes y de su tejido social "en especial reclaman por una memoria reparativa y favorece el hacer efectiva la demanda de derechos en los estados democráticos" (Acevedo-Arango, 2017). Dada la complejidad desde la cual se desenvuelven los escenarios de conflicto, para muchos sobrevivientes resulta difícil aceptar un discurso de reconciliación mientras siga existiendo un sistema donde la ilegalidad y la corrupción traspase los valores y normas que soportan la justicia, donde los diferentes gobiernos no tienen la capacidad ni la credibilidad para garantizar el respeto a la ley y la plena vigencia de los Derechos Humanos.

\subsubsection{Abordar la reparación y no repetición desde la resistencia}

Estas dos nociones de reparación y no repetición permiten, en el caso de la primera, llegar a la Reconciliación Social en la medida en que se debe dirigir a procesos que emerjan de la resistencia, donde se manifieste la creación y transformación de enfoques dialógicos que pueden guiar las reflexiones dadas desde los sujetos, los grupos y las comunidades; en este caso concreto, desde lo vivido en medio de la huerta y la cocina a partir de la preparación de alimentos y la siembra como acciones de esa resistencia. El sentido que se preserva de la cocina como un espacio de construcción colectiva y reparación surge con el fin de comprender la experiencia del desarraigo y de renacer para dar continuidad y visibilidad a las acciones por el reconocimiento y la reconstrucción de proyectos de vida de mujeres desplazadas, a través de un ejercicio práctico y reflexivo en el que la alimentación ocupa un lugar central, como canal de comunicación y de cuidado, que posibilita la expresión de sentimientos y emociones, la construcción de narrativas y el acercamiento con ese otro desconocido que en medio de tantas diferencias es preciso reconocer. Esto permite pensar entonces, a las mujeres como agentes activos en constante construcción, que ponen en marcha sus habilidades y saberes, reconociéndose como personas valiosas en busca de una formación política que oriente sus acciones y su palabra.

Tanto la cocina como la huerta son representaciones fundamentales de la Memoria Transformadora en el caso concreto de las mujeres campesinas y los excombatientes por 
varias razones: primero por el recuerdo ${ }^{2}$ que puede generar el espacio donde se gesta la siembra, el arraigo a la tierra y el recuerdo del campo -espacio construido como su hogarcomo una acción políticamente responsable, bajo el intento de darle vida en el presente a los saberes aprendidos en el campo, de ahí la trascendencia que tiene el ser responsables de nuestra propia biografía. Segundo, porque articula un tejido colectivo para la dignificación de sujetos humanos y no humanos, por los saberes de acción propios de las mujeres y los excombatientes, dado el contexto rural donde se desarrollaron además del cuidado por la tierra, la misma que ha sido sujeto de disputas, conflicto y violencias en Colombia, tomando un valor simbólico de restauración y transformación y tercero, por cómo se configuran como espacios para dar apertura a lo que Arendt denomina La condición política, que "es a la vez una fuerza interna del espíritu del hombre y una acción discursiva mediada por reales intenciones de transformación" (Díaz-Gómez, Carmona-Marín y Montañez-Holguín, 2019, p. 32), pues la intención y finalidad con la que inicia esta experiencia es de resistencia y resiliencia ${ }^{3}$ a los contextos de guerra que les tocó vivir y que les permite de algún modo dejar atrás un pasado violento y construir significados alrededor de lo que se denomina como hogar. Así lo menciona una de las mujeres campesinas partícipe del proceso,

(...) Si yo vengo aquí a disipar este día o esta semana a entretenerme, eso es paz, porque si yo estoy en la casa tirada en una cama, sin ganas de nada, qué paz voy a sentir, voy a sentir es odio, rencor conmigo misma, con los que me hicieron ese daño, con todo, con la vida y pensando en que por qué la vida es así. (Relato de mujer campesina, 2019)

Estas representaciones de la Memoria Transformadora se iban configurando como espacios públicos de cuidado, una representación de discurso-acción a través de la cual los sobrevivientes principalmente se daban la posibilidad de convivir juntos, de reconocerse y de aprender por medio de prácticas como el compartir los alimentos y la siembra. En palabras de Zapata (2006):

lo que hace que todos los hombres distintos se igualen, es precisamente, la acción-discurso necesarios en el vivir juntos. Tanto la acción como el discurso no buscan otra cosa que la permanencia en el tiempo (...) El discurso pretende preservar en la memoria el sentido del obrar. (p. 510)

Pensar en convivir con ese otro se convertía en un juego de voluntariedad que a la vez daba la posibilidad de dar respuesta a lo que cada uno desde sus particularidades buscaba, pero que solo lo permitía el exponerse en estos espacios de construcción.

2 El recuerdo no solo como un dispositivo para traer al presente impresiones que permanecen en la memoria, sino como un acto político de nueva significación.

3 El término resiliencia procede del latín de la palabra resilio, que significa volver atrás, volver de un salto, resaltar, rebotar. Richardson, Neieger, Jensen y Kumpfer definen la resiliencia como «el proceso de afrontamiento con eventos vitales desgarradores, estresantes o desafiantes de un modo que proporciona al individuo protección adicional y habilidades de afrontamiento que las que tenía previa a la ruptura que resultó desde el evento» (Becoña-Iglesias, 2006). 
En la misma vía, una reparación psicosocial en medio de estos procesos, contribuye a develar la dignidad de los sobrevivientes y sus familias, previene las causas para que no se repitan -ver ahí el valor de la memoria colectiva-, reconstruye lazos familiares y vecinales que proporcionan a la vez seguridad y confianza, en aras a garantizar por lo menos en un comienzo una coexistencia que derive con el tiempo en una convivencia pacífica. En esta noción se encuentra también la de reparación del daño a ese otro, expresado en la naturaleza $\mathrm{y}$ las formas de vida comunitarias y ancestrales que fueron trocadas y destruidas por la violencia. En el caso de la idea de no repetición, esta se soporta bajo un enfoque de respeto por los Derechos Humanos, esencial para la reconstrucción de aquellas relaciones fracturadas, haciendo visible el papel de los gobiernos en asegurar dichas garantías de no repetición, en la superación de condiciones precarias estructurales que dieron origen a la violencia armada y que compromete el marco jurídico a nivel social, político y económico.

\subsubsection{Resignificar el perdón y el olvido}

Se comprende que la Reconciliación Social no implica de manera obligatoria un proceso orientado al perdón, más bien, pretende promover una cercanía con ese otro que puede llegar a ser, en algunos aspectos de la vida, común. Esta noción de perdón suele ser derivada de aspectos religiosos que promueven en muchas ocasiones el olvido de los actos cometidos. Sin embargo, con el fin de no caer en perdones efímeros o cambios de actitud momentáneos, es preciso plantear la Reconciliación Social como un proceso o camino largo, que se enuncia más allá de recibir u otorgar una disculpa, donde emergen nuevas formas de interacción social, de resolución de conflictos y de tramitación del dolor, un terreno más que religioso, espiritual y filosófico, "Un perdón que, desde su dimensión filosófica, se acerca a la libertad kantiana, pues libera las causas de los efectos; $y$ "se corresponde con un acto de liberación tanto para la víctima como para el victimario" (Bueno-Cipagauta, 2006, p. 70) perdonar es por lo tanto una acción relacional, es a la vez una decisión, una actitud y un proceso a partir del cual se da paso a la liberación del sufrimiento, de las relaciones dolorosas, se libera entonces de la condición de víctima "ahí, donde el castigo no cubre la pérdida es donde tiene espacio el dolor” (Bueno-Cipagauta, 2006, p. 71), permitiendo emprender ejercicios de memoria que trascienden del hecho victimizante y proyectan alternativas de vida para el futuro.

(...) apenas conté mi historia, lo sentí incómodo... lo podía sentir (...) después él se acercó a la cocina y me preguntó de ¿qué parte del Cauca era?, entonces yo le respondí donde tenía el parador, el me miró y me dijo - ¿tras de su casa había una montaña, cierto? - Yo le respondí que sí y él me dijo -de esa montaña para dentro militaba yo-, (...) No sé, será porque yo ya lo conozco, pero no me causó algo malo, yo lo miraba y él se sentía incómodo, podía percibirlo... siento que 
él no sabía cómo acercarse, sin embargo, me dijo eso y yo no supe qué decirle más... al final me dijo que -esta guerra es lo que nos había tocado vivir- un poco con pena e incomodidad. (Relato de mujer campesina, 2019)

En este punto, es importante cuestionar un elemento constitutivo de la memoria, el olvido, en consecuencia, es preciso responder: ¿Qué se debe olvidar cuando hacemos Memoria Transformadora? Cuando recurrimos al olvido como elemento fundamental para hacer memoria, concebimos que lo que olvidamos no es el hecho en sí mismo, para el caso en contexto, el desplazamiento forzado o la pertenencia y salida del grupo armado, sino los significados del mismo, es decir, significado que se le otorga a dicho hecho, como por ejemplo el desarraigo, el despojo, el reclutamiento, la violencia armada, entre otros. Dichos elementos se resignificarán a través de una experiencia transformadora por lo que se recordará el hecho en sí mismo pero resignificado a través de la experiencia de manera distinta.

Entonces es necesario comprender que las emociones constituyen la vida social, "están inscritas en las relaciones, donde preexisten al lenguaje y definen la acción” (Kisnerman, 1998, p. 81). Se reconoce que en estos espacios cotidianos y de representación de la Memoria Transformadora se puede gestar, generar y resignificar nuevas emociones a través del convivir entre diferentes, empezar a compartir y reconocernos desde lo humano que nos constituye, dando apertura a la restauración de relaciones, que permita establecer lazos de confianza que posibiliten trabajar en colectividad, donde se puedan emprender acciones plurales, entendiendo que estas no solo implican el hecho de actuar con otros y para otros, sino "revelar la existente conciencia de aquellos que no temen dar a conocer la distinción de su existencia" (Díaz-Gómez, Carmona-Marín, \& Montañez-Holguín, 2019, p. 28).

Olvidar se convierte en un deber moral que nos permite pensar la reconciliación como proceso, en tanto aporta a que los sujetos puedan trascender sus dolores, tramitarlos, sanarlos y restaurar las relaciones de confianza, de colectividad y de empatía, que fueron fraccionadas en el marco del conflicto armado, así, el olvido, "en suma, es fuerza de la memoria y el recuerdo el producto de esta" (Augé, 1998, p. 28). El olvido se convierte en un elemento constitutivo e importante de la Memoria Transformadora en tanto promueve la coexistencia en un espacio dado entre los sobrevivientes, bajo el respeto por lo que el otro es, con ánimo de que los sujetos puedan tramitar esas emociones y sentimientos para que resignificados orienten su accionar en orientación a una convivencia pacífica. El recuerdo resignificado nos permite actuar, movilizarnos y emprender acciones que posibiliten transformar las formas de relacionarnos, desde la confianza, la cercanía, la diferencia, la colectividad y la pluralidad. 


\subsection{El rol profesional en escenarios de construcción de paz}

Implicarse en una experiencia transformadora junto a los sujetos que la orientan, manifiesta en medio del ejercicio profesional dilemas y cuestionamientos éticos sobre el quehacer en estos escenarios. Estar inmerso en estos procesos de construir colaborativamente la paz lleva a reconocer las múltiples caras de la guerra, la realidad vivida desde varios espacios, desde el dolor hasta la esperanza, trascendiendo una vez más, del sentido práctico de la intervención.

Pertenecer a un grupo e interactuar entre los sujetos y su contexto, revela en medio de la intervención el papel y el lugar del educador social, apostando a la construcción pedagógica de la paz acorde a particularidades culturales, étnicas, sociales, raciales, económicas y políticas, que reconocen la autonomía, la identidad y la dignidad de los sujetos. El Trabajador Social impulsa en medio de estos escenarios de construcción lazos de cercanía, de convivencia y de ciudadanía como oportunidad de establecer distintas maneras de relacionarnos, desde lo que nos distancia hasta lo que nos permite encontrarnos, las múltiples salidas negociadas al conflicto y la condición dignificada de su esencia natural.

En ese sentido se entiende el rol del Trabajador Social, como el ejercicio profesional que se manifiesta en la intervención y en medio de la interacción con los sujetos, orientado a la transformación de la realidad y las relaciones sociales, el cual se rige por la construcción ética y política del profesional. El rol implica el desarrollo de diferentes capacidades y conocimientos teórico-prácticos para lograr alcanzar los objetivos dentro de la intervención que trasciende de lo operativo y se consolida en el sentido e impacto de la acción.

El rol se manifiesta en medio de la construcción de sujetos ético políticos, lo ético, se rige por la reivindicación de los derechos, la promoción y defensa de la vida en medio del conflicto y la posibilidad del cumplimiento de los acuerdos que garanticen mejores condiciones para la construcción de la paz. En el marco de lo político, se requieren acuerdos en vía a la justicia, la equidad y la dignidad que posibiliten plantear la reconstrucción del tejido social como una edificación colectiva. Como resultado, se convierte en un rol fundamental dentro de estos procesos de Reconciliación Social, el promover espacios de diálogo y debate que permitan visibilizar los tejidos de vida de los sobrevivientes y propender por reconciliar múltiples verdades que emergen en estos contextos, garantizando la superación de propiedades polarizantes y el encuentro de las distintas memorias que se unen a la apuesta de la Memoria transformadora -colectiva, histórica- en medio de tensiones permanentes entre el olvido y el recuerdo: 
El recuerdo se convierte en memoria, en una memoria colectiva concreta, mucho más compleja y vasta en tanto articula las percepciones del recuerdo no a un pasado inefable sino a la constatación de ese pasado en prácticas concretas sedimentadas (Habitus) y en testimonio. (Acevedo-Arango, 2012, p. 48)

Por ende, el sentido que se le otorga desde la profesión a la Memoria Transformadora permite entender que el Trabajo Social a través de una lectura crítica del contexto, del conocimiento de unas dinámicas históricas, políticas, económicas, sociales y culturales, da paso a un reconocimiento de discursos que, tras ser interpelados, cuestionados o reflexionados, pueden ser encaminados a una configuración de sujetos ético-políticos que posibiliten una conciencia transformadora y a la misma vez liberadora, construida siempre en el marco de la interacción, desde una postura ética se parte de la búsqueda de un país con mayor igualdad y menos vulneración de derechos, un país donde el reconocimiento del otro guíe el accionar personal y profesional, situando al Trabajo Social desde una mirada plural, reconociendo lo valioso de otras voces en la construcción del quehacer y la identidad profesional, permitiendo construir y aprender de ese otro, no como un ente externo y distante, sino desde la comunidad, grupo u organización.

\section{Conclusiones}

Pensarse desde la profesión en medio de estos contextos nos permite precisar consideraciones desarrolladas a lo largo de estas páginas, planteadas a partir de diversas percepciones y experiencias de vida bajo ideas de construcción que permiten comprender la Memoria, aquella que posibilita la transformación y reconstrucción de vínculos quebrados a raíz de la violencia armada, en consecuencia, es importante resaltar que:

Los procesos de Reconciliación Social, se deben comprender desde la participación que involucre no solo a los sobrevivientes del conflicto armado y el Estado, sino también la sociedad en general, donde se configuren subjetividades críticas, reflexivas, activas y participativas en la transformación del tejido social. Abordar estos procesos desde la importancia de la acción en los micro contextos da posibilidad de pensar una sociedad más justa, equitativa y democrática.

La intervención desde la profesión en los procesos de Reconciliación Social debe estar orientada al reconocimiento de los actores como sujetos reflexivos, con historias y saberes particulares, que enriquecen y posibilitan su participación en los mismos. En perspectiva de futuro, se propende porque el resultado de estos procesos se consolide como una oportunidad de atacar las causas estructurales que originan y mantienen el conflicto, reparar la dignidad de los involucrados en este último y dar apertura a la reconstrucción de un proyecto de vida. 
Interpelar las categorías conceptuales a la luz de las realidades sociales en las que se está inmerso, permite alcanzar comprensiones teórico-prácticas que posibilitan orientar y dotar de sentido el accionar profesional, por ende, dentro de este proceso se propone tener en cuenta tres dimensiones fundamentales para pensar la Reconciliación Social, pues en ellas se concretan aspectos fundamentales para la restauración de relaciones, no solo con los otros y con lo otro sino también con sí mismo.

Desde Trabajo Social es necesario repensar las formas en las cuales nos relacionamos con los espacios y los actores en estos procesos, enfocarse en la potencialidad de cada uno permite construir procesos con sentidos compartidos que revelan necesidades de actuar bajo perspectivas sectoriales y de género, reparar como consecuencia de procesos políticos contenidos de acuerdos y alianzas, otorgando verdadero protagonismo a la construcción de los sujetos desde sus espacios cotidianos.

Agradecimientos: inicialmente quisiéramos agradecer de manera vehemente a cada uno de los actores sociales que participaron en el proceso, exponiéndose a partir del relato de sus vidas y la confrontación con aquellos contextos de violencia que les ha marcado, agradecemos la escucha, y la palabra tejida en cada encuentro, así como la capacidad de comprender las emociones y sentires de los otros, de su manera de actuar y pensar. Al Centro de estudios sobre conflicto, violencia y convivencia social (CEDAT) por la apertura que brindan a escenarios de construcción de conocimientos que permiten hacer parte de caminos colectivos orientados a aportar de manera significativa a la construcción de paz desde la praxis profesional. Finalmente, a nuestra asesora académica Sandra Yaneth Vallejo González por su disposición constante, su rigurosidad para el estudio de procesos que surgen en medio de la transición hacia un estado de paz, posibilitando varias de las reflexiones e ideas planteadas en el presente texto, agradecemos su vocación y la forma de trasmitir y comprender la enseñanza.

\section{Referencias bibliográficas}

Acevedo-Arango, Ó. (2012). Geografías de la memoria: posiciones de las victimas en Colombia en el periodo de justicia transicional (2005-2010). Bogotá: Pontificia Universidad Javeriana.

Acevedo-Arango, Ó. (2017). Episteme de la victimidad: reposicionar al sobreviviente y reparar a la victima. Bogotá: Universidad Santo Tomás.

Acevedo-Arango, Ó., Serrano-Quintero, L., y Cuartas-Giraldo, M. (2019). Valoración del daño y desvictimización. Violencia sociopolítica en Colombia. Bogotá: Universidad Santo Tomás. Augé, M. (1998). Las formas del olvido. Barcelona: Gedisa.

Becoña-Iglesias, E. (2006). Resiliencia: definición, características y utilidad del concepto. Revista de psicopatología y psicología clínica, 11(3), 125-146. 
Corredor-Sotelo y Fuertes-Fuertes

Bloomfield, D., Fernández, C. H., y Angulo-Novoa, A. (2015). Reconciliación: perspectivas y aportes conceptuales para su comprensión. Bogotá: CINEPP/PPP.

Bueno-Cipagauta, M. A. (2006). La reconciliación como un proceso socio-político. Aproximaciones teóricas. Reflexión política, 8(15), 64-78.

Centro de Investigación y Educación Popular y Organización Internacional para las Migraciones. (2015). Aprendizajes para la reconciliación: experiencias de reconciliación entre excombatientes y comunidades recepctoras. Bogotá, Colombia: CINEP/PPP; OIM.

Díaz-Gómez, A., Carmona-Marín, O. L., y Montañez-Holguín, M. (2019). Formación de sujetos politicos desde una experiencia de educación para la paz. Pereira: Universidad Tecnológica de Pereira.

Fraser, N. (2000). ¿De la redistribución al reconocimiento? Dilemas de la justicia en la era «postsocialista». New Left review, (0), 126-155.

Fraser, N., y Honneth, A. (2003). ¿Redistribución o reconocimiento? Un debate político-filosófico. Madrid: Paideia.

Grueso, D. I. (2008). Tres modos de involucrar el reconocimiento en la justicia. Praxis filosófica, (27), 49-71.

Jaramillo, J., y Torres, J. (octubre, 2014). La construcción de memorias públicas y transformadoras sobre el conflicto colombiano: alcances y desafios de los centros y museos de la memoria. En III Seminario Internacional de Museos: "Patrimonio, museos y memoria social". Centro de Formación de la Cooperación Española (CFCE), Cartagena de Indias, Colombia.

Kisnerman, N. (1998). Pensar el Trabajo Social: una introducción desde el construccionismo. Buenos Aires, Argentina: Lumen Humanitas.

Larrosa-Bondía, J. (2010). Sobre la experiencia. Aloma: revista de psicologia, ciències de l'educació i de l'esport, (19), 87-112.

Marina-Torres, J. A., y De la Válgoma, M. (2005). La lucha por la dignidad. Teoría de la felicidad política. Barcelona: Anagrama.

Méndez, M. L. (2011). Revisión de la literatira especializada en la reconciliación. Recuperado de http:/ /library.fes.de/pdf-files/bueros/kolumbien/08551.pdf.

Ortega, F. A. (2008). Veena Das: sujetos del dolor, agentes de dignidad. Bogotá: Universidad Nacional de Colombia.

Zapata, G. (2006). La condición política en Hannah Arendt. Papel político, 11(2), 506-523. 


\section{OTROS ARTÍCULOS DE PROSPECTIVA No. 31 DE 2021}

\section{PRESENTACIÓN}

Presentación. Reflexiones sobre desafios al publicar sistematizaciones

Rosa María Cifuentes-Gil

\section{EDITORIAL}

Reflexiones sobre Trabajo Social: aportes de la Sistematización

María Rocío Cifuentes-Patiño

\section{ARTÍCULOS}

Hacer lo que se sabe, pensar lo que se hace. La sistematización como modalidad investigativa Alfonso Torres-Carrillo

Aportes y desafios de la Sistematización de experiencias en el Trabajo Social y la extensión crítica. Apuntes y reflexiones desde la perspectiva de la Educación Popular

María Rosa Goldar

Valeria Chiavetta

La sistematización en Trabajo Social y la epistemología feminista del punto de vista. Diálogos sobre la producción de conocimiento sustentada en experiencias

Ruth Noemí Parola

María Florencia Linardelli

La Sistematización investigativa de las experiencias: del baile de los que sobran a la fiesta de los que faltan

María Belén Ortega-Senet

Sistematización y Trabajo Social en Chile. El largo y sinuoso camino

Patricia Lorena Castañeda-Meneses

Ana María Salamé-Coulon
Sentipensar la pandemia COVID-19 desde la sistematización de la experiencia en Trabajo Social: reflexiones del profesor Oscar Jara Holliday

Elia Sepúlveda-Hernández

La sistematización de experiencias, una investigación social cualitativa que potencia buenas prácticas de convivencia y gobierno. La experiencia de un conjunto residencial multifamiliar en Cali, Colombia Martha Lucia Echeverry-Velásquez Manuela Prada-Dávila

Construcción de subjetividades epistemológicaspolíticas de profesoras y profesores de Investigación social en una universidad privada y confesional en Bogotá

Giovanni Mora-Lemus

Sistematización de la experiencia Reconocimiento de los derechos humanos del adulto mayor en dos familias residentes en Cali y Valledupar (Colombia)

Lina María Cuello-Lacouture

Jimena del Pilar Jaramillo-Jaramillo

La memoria transformadora como estrategia de intervención profesional en los procesos de reconciliación social: comprensión a partir de mujeres campesinas, excombatientes y jóvenes en Manizales, Colombia

Yeimmy Stephania Corredor-Sotelo

Juliana Fuertes-Fuertes

Sistematización de una estrategia de educación informal implementada en personas privadas de la libertad en el establecimiento penitenciario de mediana seguridad y carcelario de Barranquilla, Colombia

Rafael Humberto Herrera-Mercado Rafael Alberto Zambrano-Vanegas 
Aportes significativos del proceso de intervención comunitaria con la Escuela Popular de Comunicación Alternativa Jaime Garzón de la ciudad de Cúcuta, Colombia

Carlos Lasso-Urbano

La sistematización de la intervención como metodología de investigación en Trabajo Social. Importancia práctica y teórica de la fase de recogida de datos en la intervención social según experiencia del Programa de Apoyo a las Familias en Zaragoza, España

Elisa Esteban-Carbonell

Nuria Del Olmo-Vicén

Papel de la sistematización de experiencias en los procesos de evaluación de intervenciones de salud pública en la Comuna Saludable por la Paz, Cali - Colombia

Jenny Faisury Peña-Varón

Paola Andrea Marín-Velásquez

Janeth Mosquera-Becerra

Experiencia de intervención social en hogares comunitarios integrales del barrio Alfonso Bonilla Aragón, Cali - Colombia

Julián Alexander Montaño-Cárdenas

Las políticas sociales y el gobierno de la "población indígena". Estrategias y regulaciones en el multiculturalismo chileno

Rodrigo Agustín Navarrete-Saavedra

Representaciones sociales sobre estilo de autoridad y tipos de interacción en cuidadores de residencias de protección infantil en Chile

Marcelo Gallegos-Fuentes
Carmen Gloria Jarpa-Arriagada

Reflexiones sobre inseguridad social y cuestiones penales. Una respuesta estratégica a partir de experiencias de cooperativismo con ex detenidos en Argentina

Analia Elizabeth Otero

Yael Yanina Barrera

Desarrollo y salud: la emergencia de un nuevo paradigma

Jesús María Sánchez-Ordóñez

Trabajo Social en ejercicio libre: la perspectiva profesional en España

Paula Frieiro-Padín

Tamara Fernández-Arias

Rubén González-Rodríguez

\section{RESEÑAS}

Social Work and the City: Urban Themes in 21stCentury Social Work

Felipe Saravia-Cortés

Respuestas del Trabajo Social ante emergencias sociales y problemáticas sociales complejas de México y España

Felipe Saravia-Cortés

El feminismo, el género y la profesionalización del trabajo social en Colombia (1936-2004)

Ambar Oriana Serna-Lombo

El puño invisible. Arte, revolución y un siglo de cambios culturales

Carlos Arturo Robledo-Marín

\section{PROSPECTIVA}

No. $31 \bullet$ ene.-jun. 2021

e-ISSN: 2389-993X • Universidad del Valle 